livre mercado. As políticas de negócios săo mais enfatizadas que as politicas industriais, revelando um conjunto de robustas instituiçôes e uma dinâmica para ativá-las e inter-relacioná-las.

As robustas instituiçôes sâo resultado do processo de desenvolvimento econômico japonês sintetizado no capítulo 2. Aí o autor apresenta os principais eventos da história da industrialização japonesa, procurando caracterizar os três tipos de empresa discutidos no restante do livro. Enterprise type interfirm type e factory type săo analisados no transcorrer dos períodos de 1890-1920; $1920-55$ e $1955-2000$.

Este livro de Fruin "é motivado pela busca do que é diferente nas empresas japonesas, no contexto da industrializaçāo mundial. A mais óbvia e impressionante diferença é encontrada na estrutura". Buscando descrever as estruturas industriais japonesas, $o$ autor enfatiza interaçōes entre os indivíduos, entre estes e as instituiçốes e entre as próprias instituiçốes. O resultado săo 397 páginas de excelente argumentaçäo teórica com exemplificaçôes da realidade cotidiana. Os capítulos 6 e 7 abordam as experiências da Toshiba e da Toyota, respectivamente.

Fruin estuda o sistema empresarial japonês como sendo resultado da importação e adaptação de modelos e tecnologias ocidentais à realidade oriental, ou, mais precisamente, japonesa. No Japāo, o processo de adaptação empresarial, a cada vez mais rápidas e imprevisíveis mudanças sociais, criou segundo o autor as três formas de organização industrial acima mencionadas e que, juntas, formam o Japanese Enterprise System. Enfatizando os processos de acting interdependently e learning to leam continuosly de maneira mais acentuada que aspectos economico-financeiros, o autor caracteriza o dinamismo industrial japonês.

Os motivos pelos quais os japoneses - e não os coreanos ou chineses - desenvolveram a estrutura industrial descrita por Fruin nâo são considerados de maneira convincente. Aspectos relacionados ao comércio internacional de mercadorias ou de patentes industriais também não foram explorados pelo autor. Empolgado por alguns indicadores de crescimento econômico, ele năo vê outros aspectos, como as longas jornadas de trabalho, as elevadas poupanças pủblica e privada, muitas vezes em detrimento do próprio bem-estar, e o relativamente baixo poder de compra dos trabalhadores japoneses. Não yê também setores econômicos como o da construçâo civil, aeroespacial ou qualquer outro de produção näo-seriada, onde o desempenho japonês estâ longe da excelência.

Independentemente do que o autor viu ou deixou de ver, as economias de escala, os tipos de aprendizagem $e$ de transação, săo extensivamente estudados em The Japanese enterprise system para caracterizar suas estrutu- ras cooperativas e suas estratégias competitivas. Dessa maneira, o livro deve ser lido por economistas, industriais, estudiosos da história econômica e de negócios, administradores em geral, e por todos os estudiosos do Japão.

\section{O BRASIL QUE DÁ CERTO: O NOVO CICLO DE CRESCIMENTO 1994-2005}

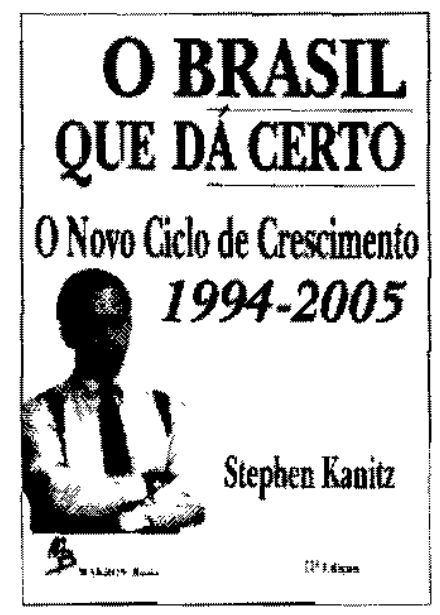

de STEPHEN CHARLES KANITZ

Säo Paulo: Makron Books, 1994, $100 \mathrm{p}$.

por Newton Hirata, Graduando em Administraçáo da Fundaçāo Universidade Estadual de Maringá.

U ma boa dose de otimismo, 30 gráficos, dez tabelas, muita informação, pequenos e grandes detalhes sobre a economia brasileira integram o cenário elaborado por Stephen Charles Kanitz, em seu livro O Brasil que dá certo: o nooo ciclo de crescimento. 1994-2005. Além disso, fatos a partir da década de 60 e projeçōes até 2005 săo analisados exaustivamente pelo autor, numa relação sempre dicotomica entre pontos positivos e negativos.

A obra se inicia com fatos da década de 60 , quando 0 pais começou a receber a poupança externa (empréstimos) e o capital externo (multinacionais) que promoveram o milagre econômico da década de 70 . Este milagre aconteceu, segundo o autor, em virtude do montante de recursos financeiros externos aplicados nos diversos setores da economia brasileira. Os investimentos geravam uma elevada taxa de retorno, entre $20 \%$ a $25 \%$ ao ano, com um custo muito baixo, de somente $3 \%$. 
Durante os anos 70 , o crescimento económico brasileiro foi vertiginoso. Entretanto, na década seguinte, começaram os problemas, um período de estagnação chamado de "década perdida". Segundo Kanitz, os bancos internacionais, em especial os americanos, simplesmente deixaram de enviar recursos. Este fluxo de dinheiro foi interrompido sem qualquer previsăo, sob a alegação, por parte dos bancos americanos, de desequilíbrio na economia brasileira e de incompetência do governo.

Para Kanitz, atribui-se o problema da dívida externa a uma questão técnica na legislaçăo bancária americana, que proíbe que seus bancos emprestem valores superiores a dez vezes os seus capitais. Este não é o agravante, pois säo nestes moldes que funcionam os bancos centrais de todo o mundo. O problema, segundo Kanitz, reside no fato de a legislação näo ter previsto as influências da inflaçâo. Como năo havia um mecanismo de correção monetária, o patrimônio líquido dos bancos estava defasado e conseqüentemente o montante de empréstimos disponiveis foi menor.

Mesmo nestas condiçòes, durante a década de 70 os bancos obtiveram excelentes lucros, maiores do que as taxas inflacionárias da época, o que possibilitava a concessão dos empréstimos. Contudo, em 1981, os índices inflacionários americanos chegaram a patamares que comprometeram a condição financeira dos bancos, não sendo possivel liberar mais recursos, näo só para o Brasil como também para mais outros 60 paises.

De acordo com Kanitz, neste periodo surgiu a imagem de um Brasil superendividado, mal administrado, financeiramente incompetente, um pais sem reservas, com risco de crédito extremamente elevado. O país, entretanto, tinha um superávit comercial. Se pensarmos como uma sociedade anônima, veremos que a dívida externa de US $\$ 180$ bilhôes era menos do que $4{ }^{2}$ da riqueza nacional.

O cenário visualizado por Kanitz é bastante animador, em virtude da análise de uma série de fatos e detaIhes que iräo alavancar o país, movido basicamente pela força de trabalho das empresas, além das condiçôes propícias que envolvem seu crescimento. Faz-se uma analogia com as condiçöes da década de 70, mantidas, obviamente, as consideraçōes específicas de cada época. A avaliaçăo ê de que o ambiente atual é mais tavorável, e espera-se que năo sejam cometidos os mesmos erros do passado.

Uma grande parcela de contribuição virá, na visăo de Kanitz, dos pequenos empreendimentos espalhados por todo o país. $O$ autor considera que o número de empreendedores é muito grande, tratando-se de pessoas, na maioria das vezes, com curso superior, com experiência em grandes empresas e decididas a montar seu próprio negócio. Muitos desses empreendedores voltam para cidades-polo do interior, com potencialidades a desenvolver, nas quais se tem a chamada qualidade de vida.

Um bom exemplo dos atuais empreendimentos no Brasil são as franquias, cujo número hoje, segundo o autor, só perde para o Japão e EUA. O índice de mortalidade destes empreendimentos é muito baixo. Segundo pesquisas, $86 \%$ são bem-sucedidas. Para Kanitz, o papel dessas empresas é treinar pequenos empreendedores e bons gerentes para a expansão dos negócios.

Acredita-se que uma das questöes fundamentais para o empresário é a preocupaçâo com a produção em grande escala e de alta qualidade, para, conseqüentemente, tornar o produto mais acessivel e competitivo. O consumidor está mais exigente. Há um aumento das classes de menor poder aquisitivo. Um dos maiores concorrentes brasileiros, segundo o autor, é a China, onde a mão-de-obra é relativamente barata e onde se produz. em grandes escalas. Basicamente, é este o motivo de se estabelecer o ano 2005 como data limite para a projeção, pois näo se sabe como estará a China nesse período.

Para Kanitz, as empresas já não se encontram tão endividadas, estão prontas para um novo ciclo de crescimento. É crescente o número de empresas com certificaçóes $1 S O$ para controle de qualidade. O número de livros de negócios traduzidos para o português é muito grande. Há uma preocupação maior em se aprimorar os processos e lécnicas de gestäo. Satisfazer as necessidades dos clientes, face à abertura de mercado e à globalização da economia, é outra importante premissa que se vern firmando.

E este o contexto em que, basicamente, se insere o Brasil, um país que reúne ótimas qualidades internas $\mathrm{e}$ externas, no qual, segundo Stephen C. Kanitz, um processo de sinergia irá permitir o crescimento.

Este livro aborda vários temas de maneira um tanto quanto superficial, mas estabelece uma conexâo precisa e clara entre eles, com ênfase no contexto inflacionário. Deve ser lido por toda pessoa que queira conhecer um pouco mais sobre a economia nacional. Kanitz, além de responsável pela publicaçáo do suplemento Melhores e Matores da revista Exame, é professor e consultor, tendo obtido vắrios prêmios nas áreas de Economia $\mathrm{e}$ Análise Financeira.

Trata-se de obra fundamental para os otimistas que

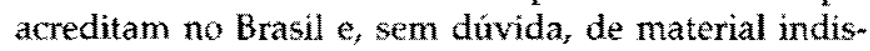
pensável aos economistas do governo, tendo em vista a gama de informaçöes apresentadas e, principalmente, as análises elaboradas. 